\title{
THE CHALLENGE OF GENUINE POWER SHARING IN PARTICIPATORY RESEARCH: THE GAP BETWEEN THEORY AND PRACTICE
}

\author{
ROBIN MASON \\ Ontario Institute for Studies in Education \\ and \\ MARIE BOUTILIER \\ North York Community Health Promotion Research Unit
}

\begin{abstract}
Participatory research is often suggested as a strategy to overcome power imbalances between researchers and research "subjects" because it values equally the knowledge of each individual who participates in the project. However, there is litule documentation of the dilenmas that may arise when a complex community service organization attempts to engage in participatory research. In our experience of a participatory research project with multiple partners, power imbalances arose from organizationally based perspectives that were unaccounted for in the participatory research literature, demonstrating that power is a complex and elusive factor in establishing equal relations.
\end{abstract}

Related to the overarching theme of this issue, "power and oppression in mental health," the problems of power in relationships between researchers and the communities they study is a critical issue. In recognizing and attempting to alleviate this problem, there has been a recent growth of interest in participatory research among community, research, and service organizations (The Royal Society of Canada, 1994). However, there is limited documentation of the dilemmas that may arise when a complex community service organization attempts to engage in participatory research. In this article we describe our initial efforts as novice participatory researchers and reflect upon our experience. We first review the tenets of participatory research, then trace the process we followed in coming to an experiential understanding of power in participatory research as organizationally based researchers working with other professionals and community members (Boutilier et al., 1995). We hope that our reflections contribute to the ongoing development of participatory research and its adaptation to various institutional and community settings.

This research was supported by the North York Community Health Promotion Research Unit, funded by the Ontario Ministry of Health. The opinions expressed in this paper are not necessarily those of the North York Community Health Promtotion Research Unit or the Ministry of Health. The authors wish to thank the reviewers for their helpful eomments on an carlier version of this paper. 


\section{WHAT IS PARTICIPATORY RESEARCH?}

The goals of participatory research are to resolve real problems while increasing the skills and knowledge base of participants. While participatory research is not a particular research method, it is a distinctive approach to research which emphasizes the equalization of power between researcher and research subject/object. Participatory researchers recognize that power accrues to those who are able both to create knowledge and to access systems of knowledge; correspondingly they recognize the oppressive implications of traditions which maintain control of knowledge and research by academy-based researchers. Participatory researchers assert that everyone has legitimate knowledge and can be an active contributor toward the creation of new knowledge (see Reitsma-Street \& Arnold, 1994). Therefore in participatory research the relationship of researcher to subject alters to one of collaboration among equal participants. The community participant's knowledge and experience are recognized as essential to the development and implementation of the research project; they bring differing but equally valued knowledge to the endeavour.

In the participatory research approach, the research problem originates within the community, not the researcher. The project seeks to answer and contribute to resolution of issues that are identified by the community participants rather than by a professional or academy-based researcher. Control of the research project lies in the community's hands. Skills are passed from the researcher to the community participants and the community comes away with some research proficiency, including a critical analysis of their issues, useful in addressing future community problems. The lives of community members are meant to be improved with the acknowledgement of the legitimacy of their knowledge, experience, and abilities; the outcomes of the research; and the critical analysis they have acquired (Brown \& Tandon, 1983; Grundy, 1982; Hall, 1993; Pan American Health Organization, 1988; Park, Brydon-Miller, Hall, \& Jackson, 1993; Rapoport, 1970).

Prior to entering the field, we read extensively within the participatory research literature and understood the major tenets and guidelines for participatory research to be:

(1) The problem originates within the community.

(2) The community maintains control of the entire process, and the researcher is committed to the community's process.

(3) Openly and clearly stating assumptions, goals, roles, and ownership of the process clarifies bases of power.

(4) Once clarified, power is equitably reallocated to all participants and reflected in their roles.

(5) The professional researcher can teach and transfer research skills to community participants.

(6) Participatory researchers work with oppressed and/or exploited community groups. The researcher facilitates the critical understanding of community participants so that oppressive conditions are made visible. 
The research leads to an awareness of the need for, if not action leading toward, fundamental structural change to address these oppressive conditions.

We followed these seven guidelines and tenets in embarking on our project; in addition, we familiarized ourselves with the community "personally as well as scientifically before starting," (Park et al., 1993), and obtained organizational support from our employer and relevant community organizations prior to entering the community. We had earlier conducted a telephone survey of health and social services in the community, asking for their view on salient community issues. Youth unemployment emerged as a key concern (Mason \& Boutilier, 1995). We then held five focus groups with youth, corroborating the findings of the telephone survey: Unemployment and worry about the future were significant concerns for youth, affecting their mental health. Subsequently we sought out community agencies and groups who would be interested in collaborating with us on a participatory research project to address issues of youth unemployment. We also read and conferred with those who had undertaken previous participatory research projects, and began our project with the anticipation that it would challenge our taken-for-granted notions of research; we were not disappointed.

\section{THE PROJECT: REFLECTIONS ON CONTEXT AND POWER}

The two-year project (1993-1995) involved three major groupings: a group of seven young people living in the community, public health nurses (two managers and three staff nurses), and researchers (two full-time university faculty members and the authors, two research unit staff researchers). We approached the project with a dual purpose: first, to develop a participatory research project that would pass on research skills both to nurses and to the community group while they investigated their priority issue. Two staff nurses and two staff researchers worked with the youth group as they carried out a local survey on the relationship between educational streaming and youth unemployment. Those data and findings belong to the youth themselves and will not be discussed here.

Second, we hoped to make a contribution to public health nursing practice that would facilitate working with community members on social determinants of health (such as unemployment), using participatory research. This component of the project focused on the reflections of researchers and public health nurses engaged in participatory research, adding a practice-based action research component to the youth-driven participatory research project. Following an understanding of "reflective practice" (Schon, 1983) as a method of integrating new learning into the daily practice within the organization, we were committed to a process of selfreflection on our respective "practices" (i,e., either nursing or research).

As a "reflective practice" research group (comprised of the staff nurses and their managers, and the university faculty and staff researchers), we maintained personal journals throughout the project. Following the completion of the youth survey component, the reflective practice group engaged in a series of four halfdity meetings to collectively consider our individual experiences and perspectives. The discussions began by creating a retrospective timeline which included each participants' expectations and subsequent experience, as captured in our journals. 
Initial expectations were that the act of reflection would enable each of us to adapt and integrate the learnings from the participatory research experience into our ongoing professional practices. We did not recognize the different everyday processes of our organizationally and discipline-based practices. For example, through the group meetings, we learned that public health nursing is characterized by ongoing dialogue and informal support among peers. On the other hand, our own experience as researchers was one of somewhat solitary and individualistic thought, reflection, and decision making.

\section{SHIFTING PERCEPTIONS OF POWER}

There may be significant differences between individuals in their perceptions of power, both their own and that held by others. Power may not be a static attribute or resource, but may increase or decrease contingent upon situations, locales, and viewpoints. This ambiguity and fluidity of power is a key factor confounding a straightforward implementation of the participatory research guidelines, but rarely is it explicitly documented in the participatory research litcrature. "Openly and clearly stating assumptions and goals" did not clarify all the sources and bases of power for the participants, nor did it prevent future power struggles from arising. For the authors, having discussed power, roles, and responsibilities with our various partners at the outset, we assumed these issues had been laid to rest. Power, however, is never laid to rest. Over many months it became clear that power reemerged in various guises, nor were the hidden assumptions and goals of the many partners fully articulated at the outset. In part, this is attributable to the very nature of assumptions. It is not always possible to be fully aware of one's assumptions, nor to articulate them until they are challenged. In part, this is also due to the nature of institutions and organizations, in that they imbue their members with a culture and expectations which can become taken for granted (or assumed) by "insiders," yet unfathomable to the "outsiders" in the collaborative effort. We developed an experiential knowledge of Foucault's point that it is the nature of power to remain unstated and hidden within professional organizations and the social relations of practice (Lemert \& Gillan, 1982).

As we were all newcomers to the participatory research process, we assumed an "equality of ignorance" among the professional partners that would lead to a sharing of knowledge and skills, coupled with a division of labour according to training-related skill and efficiency. As the university-trained staff researchers, we were directed by our superiors to take on three major tasks (beyond our own reflections): (a) to "mentor" our nursing peers in research skills as needed; (b) to "mentor" the youth group in research skills, with the youth being in control of the research questions and methods; and (c) to develop academic peer-reviewed research funding proposals for the project. By "mentoring," we assumed collaboration in which we would pass on skills in a fairly unstructured manner, providing literature or summarizing points within our own discipline-based training as necessary. Our expectations were that the "mentoring" of our professional partners in research skills would take the form of working together on specific research tasks (such as deciding on a sampling frame, or refining survey questions with the youth group). Each individual's personal research activities were to include reading. 
reflecting and committing to paper via personal journal entries, the experience or feelings invoked through sharing in this process. We considered this mentoring role to be collaborative, egalitarian, and clearly understood among all research and nursing partners. For their part, the nurses would "mentor" the researchers in establishing community relationships and small group facilitation. We later learned, however, that for our nursing partners confusion and misunderstanding around roles were developing. Our nursing partners were beginning to recognize and articulate amongst themselves the existence of power imbalances between researchers and nurses.

We believe that the power imbalances were inextricably linked to our respective positions within our organizations and their institutional expectations. First, the researcher role carried an elevated status from the nurses' perspective which we could not eliminate, although we had explained that we were all novices in participatory research. Secondly, the expectations surrounding the task of proposal development exacerbated this power imbalance. To clarify, many of the people with whom we conferred prior to our project emphasized to us the difficulty in obtaining academic peer-reviewed funding for participatory research because such projects are often dismissed as "community development" or program planning, rather than as research (Rootman, personal communication, November 1991; Hall, personal communication. April 7, 1992; Royal Society of Canada, 1994). Therefore, as our organization sought peer-reviewed funding, first, we utilized a "language" that was more academic than used in our working relationships with the nurses and the youth; secondly, we laid out a process that the project might follow. We assumed that our nursing partners shared the understanding of the "institutional expectation" of academia; that we would write academically, and that the proposals would go through several revisions before final submission and acceptance. We did not expect that for them, each proposal draft would be seen as final pronouncement. This assumption of a shared understanding of institutional expectations, in retrospect, was a miscalculation.

We subsequently learned that our front-line nursing partners believed that, as we were the professional researchers, we were withholding some knowledge or understanding from them by not laying out more clearly the research process and how it might unfold. For example, confusion arose from the many revisions of the proposal (Bresolin \& Panhuysen, 1995). Our nursing partners assumed that the project would rigidly follow the outlined process described in the proposal. The clear processes articulated in the academic proposal were not apparent to them in the flexibility we demonstrated on an everyday basis in the project itself. Our nurse partners did not directly voice their unease with this discrepancy until our collective reflections meetings. We speculate that their organizational culture did not encourage front-line questioning or participation in strategic decision making. Thus, the process of making decisions in response to external contingencies (such as $\mathrm{Re}$ quests For Proposals, or suggestions by reviewers) was unfamiliar to them.

Organizations have their own established ways and means of assigning work, allocating roles and responsibilities, and the implications of these, of course, are understood better by its "insiders" than by its partners. The flexibility necessary to renegotiate these roles and responsibilities, as and when required by the participatory research process, is not always part of an organization's culture. For ex- 
ample, initially the staff nurses' time was allocated according to open spaces on their pre-existing workload and schedules. Through working with them we came to understand their work-related time constraints. We then made an effort to act as advocates for our front-line partners to their managers to free up their time for the participatory research project. Rearranging and shifting these "resources" (as staff time is named) was not a task or responsibility that we had expected in our early discussions and role negotiations. The task fell to us because as "outsiders" to the organization we had more latitude to suggest changes to the institutionally accepted "ways and means." This task required negotiations across strata of the organizational hierarchy. We had not initially anticipated that having to negotiate within this management organizational schema would be a component of our research role. Neither did we, at the time, recognize this as accruing power to ourselves. Stepping into this negotiation with managers, however, further elevated our standing in the front-line practitioners' eyes, jeopardizing the equal relationship we had sought to establish with them.

We continued to believe that through our early discussion of power, roles, and responsibilities, we had shifted the professional power and status that we may have initially held in relation to the nurses, and continued work with them in accordance with this belief. The nurses, however, have indicated a "strain" developed for them which they were "powerless" to change: they began to appreciate that we had power and some autonomy as outsiders to the organization and as researchers, which they did not. As they were not sharing these feelings and observations with us until our group reflection process, we continued to use what had become for them the rhetoric and jargon of equality.

In considering this and other issues, we realize that the literature on participatory research did not alert us to how the complex institutional hicrarchy would be transposed onto relationships at the individual level within the research process. In effect, we were trying to graft an alternate model of relations onto the organization-one that shifts power relationships, and therefore was in conflict with the organization's structure. The hegemony of the organizational culture, however, withstood our group's efforts to stand outside it for the purposes of the project.

We learned that power was accorded us on the basis of our association with a powerful institution and that power was independent of our own feelings of power, or powerlessness within that organization. This was difficult for us to hear because we felt ourselves to be in a similar institutional location. The status of elite institutions (in our case the university) carries more weight than the individuals within it. Only through seeing from the perspective of outsiders the value they placed on our positions, did we come to recognise, acknowledge, and name our own power.

\section{CONCLUSION: SHARING POWER IS NOT ENOUGH}

Through this experience we learned that the early identification of one's personal professional power does not redistribute it or dismiss it, but may simply mean it is no longer articulated, and thus is not allowed to be spoken of by others. The discussion of power may be driven underground, rather than remaining an ongoing topic for open discussion. As noted earlier, significant differences exist 
between individual perceptions of power; the positions individuals hold within an organization can determine their view of the power held by others. We believe that the relations of power were unwittingly reproduced between ourselves and the staff nurses because we underestimated the strength of these differences.

Participatory research has become popular as a means of addressing power imbalances in research and service provision. However, as we have learned, the organizational implementation of participatory research can raise dilemmas for researchers and practitioners; it requires a flexibility and autonomy seldom accorded front-line practitioners and it can stimulate an uncomfortable examination of one's personal power within one's organization and within the project itself. Continual open discussion of power and position within a project may help alleviate the assumption that power and equality are static entities that can be easily shared. We learned that participatory research facilitates the critical understanding of all participants, making visible relations of power throughout the project and the par-ticipating organizations, regardless of initial intention. Adoption of participatory research, then, requires commitment to self-examination, reflection, and communication at both the individual and the organizational levels.

\section{NOTES}

1. For an analysis of power relationships in participatory research, see Conchelos and Kassam (1981), Hall (1981), and Maguire (1987).

\section{RÉSUMÉ}

II est souvent suggéré que la recherche participative est une stratégie visant à rééquilibrer les relations entre les chercheurs et les participants, puisqu'elle permettrait de traiter sur un pied d'égalité les connaissances de chacun. II existe toutefois très peu de documentation concernant les dilemmes auxquels est confrontée une agence de services communautaires lorsqu'elle tente d'entreprendre une recherche participative. D'après notre expérience lors d'un projet de recherche participative en multipartenariat, les déséquilibres dans les relations étaient dus à des perspectives organisationnelles différentes. Or ces facteurs ne semblent pas pris en considération dans les écrits sur la recherche participative, ce qui peut contribuer à la difficulté de définir des relations égalitaires.

\section{REFERENCES}

Boutilier, M., Mason, R., Rootman, I., Roberson, A., Bresolin, L., Panhuysen, N., Tao, M., Sage, L., \& Marz, C. (1995). Can the 2-step become a square dance?: Participatory action research with community residents, agencies, public health and the university. Paper presented at the annual meeting of the Ontario Public Health Association, London, ON.

Bresolin, L., \& Panhuysen, N. (1995). The nurse researcher: Images of role strain. Unpublished paper, North York Public Health Department, North York, ON.

Brown, J., \& Tandon R. (1983). Ideology and political economy in inquiry: Action research and participatory research. Joumal of Applied Behavioral Science, I9(3), 277-294.

Conchelos, G., \& Kassam, Y. (1981). A brief review of critical opinions and responses on issues facing participatory research. Convergence, 14(3), 52-63.

Grundy, S. (1982). Three modes of action research. Curriculam Perspectives, 2(3), 23-34. 


\section{CANADIAN JOURNAL OF COMMUNITY MENTAL HEALTH}

Hall, B. (1981), Participatory research, popular knowledge and power: A personal reflection. Convergence, $14(3), 6-19$.

Hall, B. (1993). Introduction. In P. Park, M. Brydon-Miller, B. Hall, \& T. Jackson (Eds.), Voices of change: Participatory research in the United States and Canada (pp. xiii-xxii), Toronto: OISE Press.

Lemert, C., \& Gillan, G. (1982). Michel Foucault: Social theory and transgression. New York: Columbia University Press.

Maguire, P. (1987). Doing participatory research: A feminist approach. Amherst, MA: The Center for International Education, University of Massachusetts.

Mason, R., \& Boutilier, M. (1995). Unemployment as an issue for public health: Results of a telephone survey. Canadian Joumal of Public Health, 86(3), 152-154.

Pan American Health Organization. (1988), Guidelines for the development of participatory action-oriented research projects. Washington, DC: Health Services Development Program, Series 65.

Park, P., Brydon-Miller, M., Hall, B., \& Jackson, T. (Eds.). (1993). Voices of change: Participatory research in the United States and Canada. Toronto: OISE Press.

Rapoport, R. (1970). Three dilemmas in action research. Human Relations, 23, 499-513.

Reitsma-Street, M., \& Arnold, R. (1994). Community-based action research in a multi-site prevention project: Challenges and resolutions. Canadian Joumal of Community Mental Health, 13(2), 229-240.

Royal Society of Canada. (1994, May). Meeting on participatory research, Montreal.

Schon, D. (1983). The reflective practitioner: How professionals think in action. New York: Basic Books. 